\section{Off-label use of tofacitinib: a potential treatment option for SAPHO syndrome}

Synovitis, acne, pustulosis, hyperostosis and osteitis (SAPHO) syndrome is a rare and often under-reported autoimmune disease, characterised by prominent cutaneous and articular inflammation. ${ }^{1}$ SAPHO syndrome is initially classified within spondyloarthritis, whereas recent evidence indicated that it is preferable as a primitive inflammatory osteitis. There are currently no formal evidence-based guidelines regarding the management of SAPHO syndrome, although variable degrees of efficacy of pharmacological therapies have been previously described, including non-steroidal anti-inflammatory drugs, glucocorticoids, diseasemodifying antirheumatic drugs, bisphosphonates and even antibiotics. ${ }^{2}$ Moreover, antitumour necrosis factor (TNF), interleukin (IL)-1 receptor antagonist also showed beneficial effect to the refractory SAPHO patients. ${ }^{3}$ Nonetheless, treatment failure or paradoxical effect is still frequent in daily practice.

Tofacitinib is a potent, Janus kinase (JAK) $1 / 3$ inhibitor, which has been approved to treat immune-mediated diseases (IMDs), including rheumatoid arthritis, psoriatic arthritis and ulcerative colitis. ${ }^{4}$ In light of the important pathogenic role of the JAK/signal transducer and activator of transcription (STAT) pathway in IMDs, tofacitinib is being increasingly off-label used for the rheumatic diseases, especially for conditions refractory to currently standard treatment algorithms, including dermatomyositis/polymyositis, systemic sclerosis, systemic lupus erythematosus. ${ }^{5}$ Most recently, a pilot study conducted by Li et al from Peking Union Medical College Hospital, in which worldwide largest cohort of SAPHO patients have been established since 2004, retrospectively, analysed the efficacy of tofacitinib $5 \mathrm{mg}$ two times per day in 12 female patients with SAPHO syndrome. ${ }^{6}$ Overall, significant multidimensional improvements were observed regarding pain, skin lesions, systemic inflammation, quality of life and remission on MRI. Of note, tofacitinib $5 \mathrm{mg}$ two times per day was also beneficial for patients with an inadequate response to anti-TNF or bisphosphonates.

The understanding of SAPHO syndrome remained extremely stagnant. Recent studies revealed the potential role of cytokine dysregulation, such as TNF- $\alpha$, IL-1 $\beta$, IL-8, IL-17 and IL-18. ${ }^{27-9}$ The effectiveness of tofacitinib would be expected to be associated with its potent and broad suppression of cytokine network via direct and indirect manner. In addition, tofacitinib has been documented to suppress osteoclast-mediated bone resorption by inhibiting the receptor activator for nuclear factor $\mathrm{kB}$ ligand (RANKL) pathway. ${ }^{10}$ The efficacy of tofacitinib strongly suggested the role of JAK-STAT signalling pathway in the pathogenesis of SAPHO syndrome. Li's study indeed provides an important therapeutic option for refractory SAPHO patients who have failed with biologics therapies, but further observation is needed due to the limitations in design and sample size. Furthermore, identifying characteristics of patients and disease subtypes which may hint benefit from tofacitinib therapy deserves consideration in the setting of the complexity and heterogeneity of SAPHO syndrome.
Wenhui Xie $\bullet$, Hong Huang, Zhuoli Zhang $\odot$

Department of Rheumatology and Clinical Immunology, Peking University First Hospital, Beijing, China

Correspondence to Professor Zhuoli Zhang, Department of Rheumatology and Clinical Immunology, Peking University First Hospital, Beijing 100034, China zhuoli.zhang@126.com

Contributors WX and HH wrote the paper. ZZ reviewed and edited the manuscript.

Funding The authors have not declared a specific grant for this research from any funding agency in the public, commercial or not-for-profit sectors.

Competing interests None declared.

Patient and public involvement Patients and/or the public were not involved in the design, or conduct, or reporting, or dissemination plans of this research.

Patient consent for publication Obtained.

Provenance and peer review Not commissioned; internally peer reviewed. (c) Author(s) (or their employer(s)) 2020. No commercial re-use. See rights and permissions. Published by BMJ.

\section{Check for updates}

To cite Xie W, Huang H, Zhang Z. Ann Rheum Dis Epub ahead of print: [please include Day Month Year]. doi:10.1136/annrheumdis-2020-217854

Received 4 May 2020

Revised 7 May 2020

Accepted 7 May 2020

\section{Linked}

- http://dx.doi.org/10.1136/annrheumdis-2020-217956

Ann Rheum Dis 2020;0:1. doi:10.1136/annrheumdis-2020-217854

\section{ORCID iDs}

Wenhui Xie http://orcid.org/0000-0002-3881-0266

Zhuoli Zhang http://orcid.org/0000-0001-7219-9141

\section{REFERENCES}

1 Nguyen MT, Borchers A, Selmi C, et al. The SAPHO syndrome. Semin Arthritis Rheum 2012:42:254-65.

2 Firinu D, Garcia-Larsen V, Manconi PE, et al. Sapho syndrome: current developments and approaches to clinical treatment. Curr Rheumatol Rep 2016;18:35.

3 Daoussis D, Konstantopoulou G, Kraniotis P, et al. Biologics in SAPHO syndrome: a systematic review. Semin Arthritis Rheum 2019:48:618-25.

4 Xie W, Zhang Z. Tofacitinib in cardiovascular outcomes: friend or foe? Rheumatology 2020:keaa090.

5 Zhao Z, Ye C, Dong L. The off-label uses profile of tofacitinib in systemic rheumatic diseases [published online ahead of print, $2020 \mathrm{Apr} 10$ ]. Int Immunopharmacol 2020;83:106480.

6 Li Y, Huo J, Cao Y, et al. Efficacy of tofacitinib in synovitis, acne, pustulosis, hyperostosis and osteitis syndrome: a pilot study with clinical and MRI evaluation. Ann Rheum Dis 2020:annrheumdis-2020-217250.

7 Firinu D, Barca MP, Lorrai MM, et al. Th17 cells are increased in the peripheral blood of patients with SAPHO syndrome. Autoimmunity 2014;47:389-94.

8 Hurtado-Nedelec M, Chollet-Martin S, Nicaise-Roland P, et al. Characterization of the immune response in the synovitis, acne, pustulosis, hyperostosis, osteitis (SAPHO) syndrome. Rheumatology 2008;47:1160-7.

9 Liao H-J, Chyuan I-T, Wu C-S, et al. Increased neutrophil infiltration, IL-1 production and a SAPHO syndrome-like phenotype in PSTPIP2-deficient mice. Rheumatology 2015;54:1317-26.

10 LaBranche TP, Jesson MI, Radi ZA, et al. Jak inhibition with tofacitinib suppresses arthritic joint structural damage through decreased RANKL production. Arthritis Rheum 2012:64:3531-42. 